\title{
Upregulation and activation of $\delta$-opioid receptors promotes the progression of human breast cancer
}

\author{
YANG-CHAO WEI ${ }^{1,2^{*}}$, BIN ZHANG $^{3,4^{*}}$, XUAN LI $^{2^{*}}$, XIAO-MENG LIU ${ }^{5}$, JING ZHANG $^{2}$,

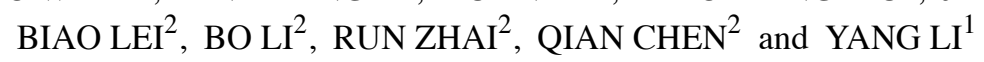 \\ Departments of ${ }^{1}$ Medical Oncology and ${ }^{2}$ Hepatobiliary Surgery, Affiliated Hospital of Guilin Medical University, Guilin, \\ Guangxi 541001; ${ }^{3}$ Department of Breast and Thyroid Surgery, The First Hospital of Jining, Jining, Shandong 272011; \\ ${ }^{4}$ Department of Medical Oncology, The First Affiliated Hospital of Dalian Medical University, Dalian, \\ Liaoning 116011; ${ }^{5}$ Department of Radiation Oncology, Shandong Cancer Hospital and Institute, \\ Shandong University, Jinan, Shandong 250017, P.R. China
}

Received February 18, 2016; Accepted March 26, 2016

DOI: 10.3892/or.2016.5109

\begin{abstract}
DOR) belongs to the family of G protein-coupled receptors (GPCRs). Numerous studies have shown that DOR is widely distributed in human peripheral tissues and is closely related to the development and progression of certain malignant tumours. However, there is controversy in the literature regarding whether DOR has an impact on the development and progression of human breast cancer. The present study comprehensively elaborates on the biological functions of DOR by determining the distribution of DOR expression in breast cancer tissues and cells and by further verifying the effects of DOR on breast cancer progression. DOR was found to be highly expressed in human breast cancer tissues and cells. In addition, the high expression level of DOR positively correlated with tumour grade and clinical stage and negatively correlated with breast cancer metastasis and prognosis. Upregulating and activating DOR promoted the proliferation of human breast cancer cells in a concentration-dependent manner within a specific concentration range, whereas downregulating or inhibiting DOR activation significantly suppressed cell proliferation. The majority of tumour cells were arrested in G1 phase, and some cells exhibited apoptosis. DOR upregulation and activation induced protein
\end{abstract}

Correspondence to: Dr Yang Li, Department of Medical Oncology, Affiliated Hospital of Guilin Medical University, 15 Lequn Road, Guilin, Guangxi 541001, P.R. China

E-mail: 1223360697@qq.com

Dr Qian Chen, Department of Hepatobiliary Surgery, Affiliated Hospital of Guilin Medical University, 15 Lequn Road, Guilin, Guangxi 541001, P.R. China

E-mail: numen_boy@163.com

*Contributed equally

Key words: breast cancer, $\delta$-opioid receptor, cell cycle, apoptosis, $\mathrm{G}$ protein-coupled receptor kinase $\mathrm{C}(\mathrm{PKC})$ activation, resulting in increased phosphorylation levels of extracellular signal-regulated kinases (ERKs). After inhibition of the PKC/ERK signalling pathway, the effects of DOR on breast cancer were significantly attenuated in vivo and in vitro. In summary, DOR is highly expressed in breast cancer and is closely related to its progression. These results suggest that DOR may serve as a potential biomarker for the early diagnosis of breast cancer and may be a viable molecular target for therapeutic intervention.

\section{Introduction}

Breast cancers are one of the major diseases that endanger human life and health. Breast cancer ranks first among the malignant tumours diagnosed in women and is a major disease that threatens women's health. The incidence of breast cancer has shown a continuing upward trend year after year (1-3). Early diagnosis and effective treatment are critical for most breast cancer patients to achieve prolonged survival and improved prognosis. Therefore, clarification of the molecular mechanisms underlying the development and progression of breast cancer and the identification of more effective diagnostic markers and therapeutic targets are required to improve the overall efficiency of breast cancer treatments.

$\delta$-opioid receptor (DOR) belongs to the $G$ protein-coupled receptor (GPCR) family $(4,5)$. The endogenous ligands of DOR are opioid peptides $(6,7)$. DOR is widely distributed in the body, including the heart (8), the gastrointestinal (GI) tract (9-11), the immune system (12) and the reproductive system (13-15). Studies have revealed that DOR is involved in the development and progression of certain malignant tumours. Debruyne et al found that DOR agonists affect the invasion of HCT-8/E11 colon cancer cells in a concentration-dependent manner (16). Kuniyasu et al found that the functional status of DOR plays an important regulatory role in the metastasis of colorectal cancer to the liver (17). Schreiber et al found that DOR is highly expressed in small cell lung cancer, and the sequence of DOR mRNA expressed in lung cancer shares homology with the DOR sequence in the brain (18). These findings indicate that DOR exerts certain biological activities on various 
types of tumours. The $\mu$-opioid receptor gene polymorphism observed in breast cancer is a highly significant risk factor for the development and progression of breast cancer (19). The present study found that the activation of DOR promoted the proliferation of human breast cancer cells.

Protein kinase C (PKC) is widely distributed throughout the human body. PKC regulates the proliferation and differentiation of a variety of cells (20-22); furthermore, activated PKC promotes the proliferation of a variety of tumour cells (23), including breast cancer cells $(24,25)$. Moreover, DOR-specific agonists activate PKC, which induces the activation of extracellular signal-regulated kinases (ERKs) (26). ERKs belong to the mitogen-activated protein kinase (MAPK) family and include two subtypes, the ERK1 and 2. ERKs participate in various biological processes, including cell growth, cell proliferation and apoptosis (27). Studies have found that DOR promotes cell proliferation through ERK pathways. This phenomenon has been confirmed in PC12 cells, SH-SY5Y cells and cardiomyocytes (28-30). Therefore, we hypothesized that DOR regulates the progression of breast cancer via the PKC/ERK signalling pathway.

The goal of the present study was to verify the effect of DOR on the development and progression of breast cancer through the examination of DOR expression in breast cancer tissues and cells. Our results showed that DOR was widely expressed in breast cancer tissues and cells, exogenous activation of DOR promoted the proliferation of breast cancer cells in a concentration-dependent manner and the PKC/ERK signalling pathway played an important role in these processes.

\section{Materials and methods}

Collection of breast cancer tissue samples. This study was approved by the Ethics Committee of the Affiliated Hospital of Guilin Medical College. Tissue samples and clinical data were collected after the patients or their families signed the informed consent documents. All 62 breast cancer and paracancerous tissue samples (tissues located $>2 \mathrm{~cm}$ away from the tumour resection margins) examined in the present study were derived from the surgical resection specimens preserved during the 2007-2009 period at the Department of Breast Surgery, Affiliated Hospital of Guilin Medical College. The tissue samples were subjected to pathological examination and associated with complete clinical information. All surgical resection specimens were separately packed and stored in liquid nitrogen within $30 \mathrm{~min}$ of resection. None of the patients received palliative surgery, radiotherapy, chemotherapy or other related treatments prior to the surgical resection.

The patients were comparable in terms of age, menopausal status, family history of cancer, ethnicity, pathological type and grade, tumour size, axillary lymph node metastasis and clinical stage. The differences in these parameters were not statistically significant. The histological grade of the breast tumours were assessed according to the World Health Organization (WHO) standards and were classified into grades I-III. Tumour stage was determined based on the seventh edition of the tumour-node-metastasis (TNM) classification of malignant tumours published by the American Joint Committee on Cancer (AJCC) and the Union for International Cancer Control (UICC). The 62 patients were followed up for five consecutive years and were required to undergo a computed tomography (CT) scan and ultrasound once every 6 months.

Cell culture. MCF-10F human breast epithelial cells and MCF-7, MDA-MB-231 and SKBR-3 human breast cancer cells were purchased from the Cell Bank of Shanghai Institute of Cell Biology, Chinese Academy of Sciences. The human breast epithelial cells and breast cancer cells were cultured in Dulbecco's modified Eagle's medium (DMEM) and Roswell Park Memorial Institute (RPMI)-1640 medium, respectively. All media were supplemented with $10 \%$ fetal bovine serum (FBS), $100 \mathrm{U} / \mathrm{ml}$ of penicillin and $100 \mathrm{U} / \mathrm{ml}$ of streptomycin. The cells were cultured at $37^{\circ} \mathrm{C}$ in a humidified $5 \%$ $\mathrm{CO}_{2}$ incubator.

Cell transfection. Breast cancer cells were maintained at a logarithmic growth phase until $75 \%$ confluency. The cells were then transduced with $5 \mu \mathrm{l}$ of virus (titre, $1.0 \times 10^{9} \mathrm{TU} / \mathrm{ml}$ ). In addition, polybrene was added to each well of cells. After $12 \mathrm{~h}$ of viral infection, the virus-containing medium was replaced with fresh conventional culture medium, and the cultured cells remained at $37^{\circ} \mathrm{C}$ in a $5 \% \mathrm{CO}_{2}$ incubator. At 4 days after viral infection, fluorescence within the cells was observed and photographed. In addition, the mRNA or total protein was extracted based on the goals of each experiment.

Reverse transcription polymerase chain reaction (RT-PCR). The total RNA was extracted from breast cancer tissues and cells using the TRIzol method. After quantification, total RNA was reverse transcribed into total complementary DNA (cDNA) using the Takara RT kit in accordance with the manufacturer's instructions. The PCR was performed using the cDNA as a template and the appropriate proportion of pre-synthesized PCR primers. The sequences of the DOR primers were 5'-ACCAAGATCTGCGTGTTCCT-3' for the upstream primer and 5'-CGATGACGAAGATGTGGATG-3' for the downstream primer. The sequences of the $\beta$-actin primers were 5'-CTGGGACGACATGGAGAAAA-3' for the upstream primer and 5'-AAGGAAGGCTGGAAGAGTGC-3' for the downstream primer. The volume of the PCR reaction was $50 \mu 1$. The PCR reaction conditions consisted of 31 cycles of $94^{\circ} \mathrm{C}$ for $2 \mathrm{~min}$, denaturation at $94^{\circ} \mathrm{C}$ for $30 \mathrm{sec}$, annealing at $55^{\circ} \mathrm{C}$ for $30 \mathrm{sec}$ and elongation at $72^{\circ} \mathrm{C}$ for $30 \mathrm{sec}$. The obtained PCR products were subjected to agarose gel electrophoresis $(1.5 \%$ gel). The gel was scanned and analysed using a gel imaging system.

Western blot analysis. The total protein was extracted from tissues and cells and quantified using the bicinchoninic acid (BCA) assay. The protein samples were subjected to sodium dodecyl sulphate-polyacrylamide gel electrophoresis (SDS-PAGE) and then transferred to nitrocellulose membranes. The membrane was blocked at $4^{\circ} \mathrm{C}$ overnight in a Tris-buffered saline/Tween-20 (TBST) blocking solution containing 5\% non-fat dry milk. After blocking, the membrane was incubated with the primary antibody at $37^{\circ} \mathrm{C}$ for $1 \mathrm{~h}$. The membrane was washed three times for $10 \mathrm{~min}$ each wash with TBST and then incubated with the secondary antibody at $37^{\circ} \mathrm{C}$ for $1 \mathrm{~h}$. The membrane was washed three more times 
for $10 \mathrm{~min}$ each wash with TBST. Subsequently, the proteins were visualized using enhanced chemiluminescence (ECL) reagents. The images were scanned and analysed.

Cell viability assay. Logarithmically growing cells were selected. Each group of cells was treated for $48 \mathrm{~h}$. Subsequently, the cells were incubated in the presence of $20 \mu \mathrm{l}$ of 3-(4,5-dimethylthiazol-2-yl)-2,5-diphenyltetrazolium bromide (MTT) $(5 \mathrm{mg} / \mathrm{ml})$ for $4 \mathrm{~h}$ at $37^{\circ} \mathrm{C}$ in a $5 \% \mathrm{CO}_{2}$ incubator. The spent solution was discarded and $150 \mu \mathrm{l}$ of dimethyl sulphoxide was added to each well of cells. The cells were then agitated at low speed for $10 \mathrm{~min}$ on a shaker at room temperature. The optical density $\left(\mathrm{OD}_{490}\right)$ value was determined using a microplate reader.

Cell cycle analysis. The cells were collected and fixed with pre-cooled $70 \%$ ethanol at $4^{\circ} \mathrm{C}$ overnight. The cell density was adjusted to $1 \times 10^{6}$ cells $/ \mathrm{ml}$. Subsequently, $50 \mathrm{mg} / 1$ of RNase, $100 \mathrm{mg} / \mathrm{l}$ of propidium iodide (PI) and $1 \mathrm{ml} / \mathrm{l}$ of Triton X-100 were added to the cells. The cells were incubated in the dark for $15 \mathrm{~min}$, and the labelled cells were examined by flow cytometry.

Examination of apoptosis. The cells were digested with trypsin and then resuspended at a density of $1 \times 10^{6}$ cells $/ \mathrm{ml}$. After the addition of $5 \mu \mathrm{l}$ of Annexin V-fluorescein isothiocyanate (FITC) and PI, the cells were incubated at $37^{\circ} \mathrm{C}$ for $15 \mathrm{~min}$ in the dark. Subsequently, the cells were analysed by flow cytometry.

Generation of tumour-bearing nude mice. The animal experiments were conducted after receiving approval from the Medical Ethics Committee of Guilin Medical College. All the mice used in the present study were purchased from the Experimental Animal Centre of Guilin Medical College. The mice were male, aged 6-8 weeks, and weighed $20 \pm 0.5 \mathrm{~g}$. The mice were randomly divided into two groups, and each group contained five mice. Xenograft tumours were established using the conventional method of subcutaneous inoculation. Four weeks later, the mice were euthanized by cervical dislocation. The xenograft tumours were collected for subsequent experiments.

Statistical analysis. All experimental data were subjected to statistical analysis using SPSS 16.0 statistical software. The quantitative data were expressed as the means \pm standard deviation. Comparisons between two groups were conducted using t-tests. The relationship between DOR and clinical pathology data was assessed using the Chi-square test. The differences in survival rate were assessed using the Kaplan-Meier survival analysis. In addition, survival rates were compared between the groups using the log-rank test. $\mathrm{P}<0.05$ indicated a statistically significant difference between two groups.

\section{Results}

DOR is highly expressed in human breast cancer tissues and cells. RT-PCR and western blot analysis were completed to analyse DOR expression in breast cancer tissues and cells. The examination of the 62 breast cancer and paracancerous tissues revealed that DOR mRNA was highly expressed in cancer tissues. In contrast, the corresponding paracancerous tissues either expressed a low level of DOR mRNA or showed no DOR mRNA expression $(\mathrm{p}<0.05)$. Among the examined cell lines, MCF-7 and SKBR-3 cells highly expressed DOR, and MDA-MB-231 and MCF-10F cells showed low or no DOR expression $(p<0.05)$ (Fig. 1A). To further verify the RT-PCR results, a western blot analysis was performed. The results showed that the expression level of DOR protein was significantly higher in breast cancer tissues than in the corresponding paracancerous tissues $(\mathrm{p}<0.05)$. In addition, the expression level of DOR protein was higher in various types of breast cancer cells than in normal breast epithelial cells $(\mathrm{p}<0.05)$ (Fig. 1B).

The relationship between DOR expression and the clinical characteristics of breast cancer. The relationship between DOR expression in breast cancer and clinical pathology data was examined. Among the 62 breast cancer patients, 54 patients $(83.1 \%)$ showed high DOR expression in cancer tissues, whereas only 19 patients (30.6\%) showed DOR expression in paracancerous tissues. This difference was statistically significant $(\mathrm{p}<0.05)$. DOR expression was positively correlated with tumour metastasis $(p<0.05)$ and clinical stage $(p<0.05$, Table I). In contrast, no correlation existed between DOR expression and other clinical parameters, including age, tumour size, tumour location and the presence/absence of tumour recurrence.

The relationship between DOR expression and survival. All of the patients were subjected to regular follow-ups. The Kaplan-Meier survival curves were analysed, and the results showed that the overall survival rate was significantly lower in patients from the DOR-positive group when compared with the DOR-negative group (Fig. 2). The survival rates were compared between the groups using a log-rank test, and the results revealed that high DOR expression was related to a poor prognosis in breast cancer patients $(\mathrm{p}<0.05)$. The results indicate that high DOR expression exerted an adverse effect on the prognosis of patients with breast cancer.

Activation of DOR promotes the proliferation of human breast cancer cells. Based on the expression status of DOR in breast cancer cells, we selected two cell lines, MCF-7 and SKBR-3, to investigate the effect of DOR on the proliferation of breast cancer cells. [D-Ala ${ }^{2}$, D-Leu ${ }^{5}$ ]enkephalin (DADLE) is a specific DOR agonist. The proliferation rates of the breast cancer cells after DADLE treatment were determined using an MTT assay. The $\mathrm{OD}_{490}$ value of the breast cancer cells showed a gradual dose-dependent increase at DADLE concentrations between $10 \mathrm{nM}$ and $1.0 \mu \mathrm{M}$. In contrast, the $\mathrm{OD}_{490}$ value of the control group did not significantly change $(\mathrm{p}<0.05)$. However, when the concentration of DADLE exceeded $1.0 \mu \mathrm{M}$, the $\mathrm{OD}_{490}$ value of the breast cancer cells did not show a further increase (Fig. 3). The results demonstrate that activation of DOR promoted the proliferation of human breast cancer cells. In addition, this DOR effect was concentration-dependent.

DOR inhibits breast cancer progression in vitro. The RNA interference (RNAi) technique was employed to silence 
Table I. Clinical characteristics.

\begin{tabular}{|c|c|c|c|}
\hline & No. & $\chi^{2}$ & P-value \\
\hline Age (years) & & 0.087 & 0.768 \\
\hline$\leq 45$ & 24 & & \\
\hline$>45$ & 30 & & \\
\hline Tumour size $(\mathrm{cm})$ & & 0.245 & 0.620 \\
\hline$\leq 2$ & 32 & & \\
\hline$>2$ & 22 & & \\
\hline Tumour location & & 0.006 & 0.940 \\
\hline Left breast & 21 & & \\
\hline Right breast & 33 & & \\
\hline Axillary lymph node & & 23.852 & 0.000 \\
\hline 0 & 6 & & \\
\hline $1-3$ & 35 & & \\
\hline$>4$ & 13 & & \\
\hline Clinical stage & & 4.059 & 0.044 \\
\hline I-II & 35 & & \\
\hline III & 19 & & \\
\hline Relapse & & 0.221 & 0.638 \\
\hline Yes & 18 & & \\
\hline No & 36 & & \\
\hline
\end{tabular}

A

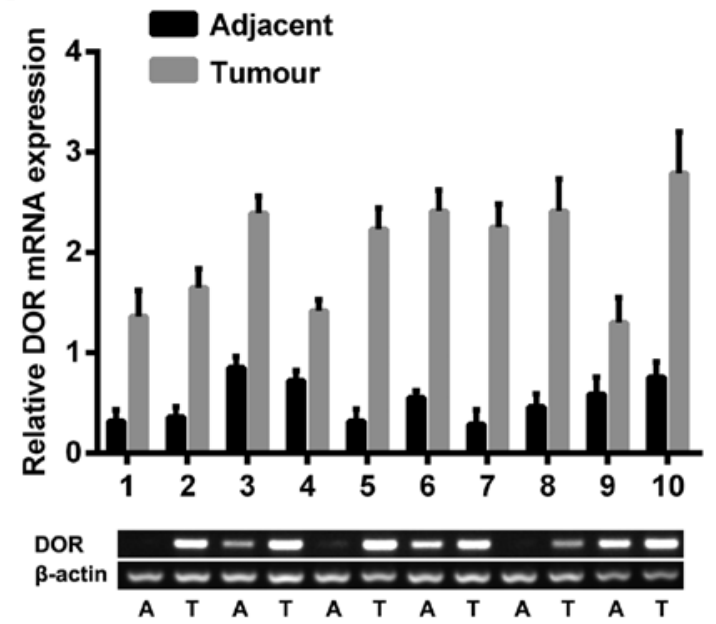

B

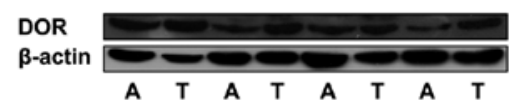

$\begin{array}{llllllll}\text { A } & \text { T } & \text { A } & \text { T } & \text { A } & \text { T } & \text { A } & \text { T }\end{array}$
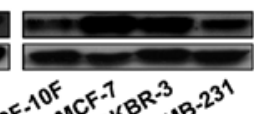

Figure 1. The $\delta$-opioid receptor (DOR) expression level is elevated in human breast cancer tissues and cells. (A) Examination of DOR expression in tumour and paracancerous tissues using reverse transcription polymerase chain reaction (RT-PCR). (B) The examination of DOR expression in tumour tissues, paracancerous tissues and tumour cells using western blot analysis. Each independent experiment was repeated in triplicate.

DOR expression in the breast cancer cell line MCF-7. A 48-h siDOR transfection led to the successful silencing of DOR expression. The $\mathrm{OD}_{490}$ value was significantly lower in the

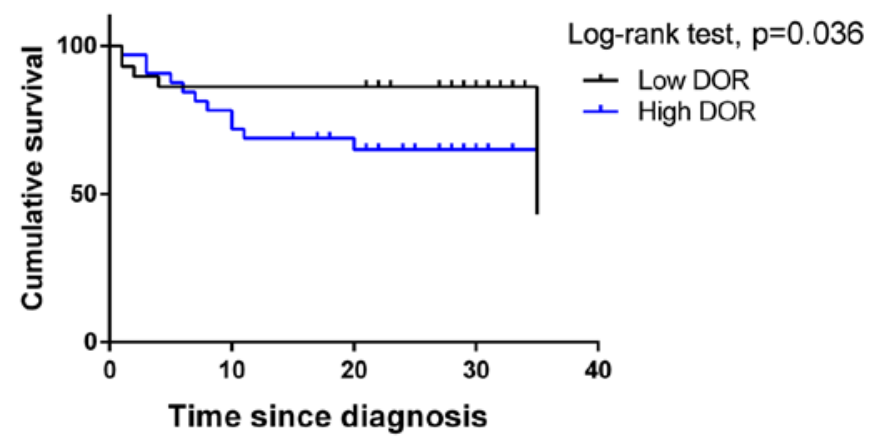

Figure 2. Evaluation of the relationship between $\delta$-opioid receptor (DOR) and the prognosis of patients with breast cancer using the Kaplan-Meier survival analysis $(\mathrm{p}<0.05)$.

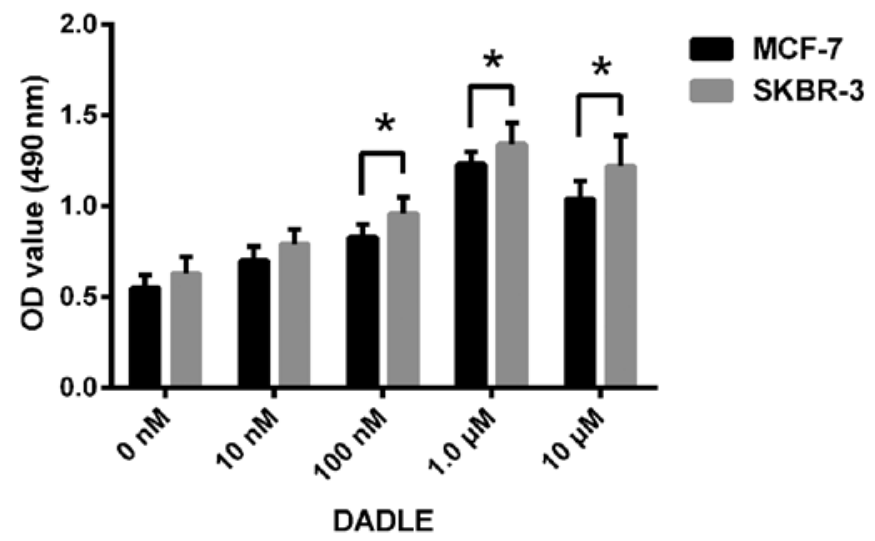

Figure 3. $\delta$-opioid receptor (DOR) promotes breast cancer cell proliferation. MCF-7 and SKBR-3 cells were treated with various concentrations of $\left[\mathrm{D}-\mathrm{Ala}^{2}, \mathrm{D}-\mathrm{Leu}^{5}\right]$ enkephalin (DADLE) $(0,10,100,1.0$ and $10 \mu \mathrm{M})$ for 48 h.Subsequently, the cell viability was examined using the MTT assay. Compared with the control group, ${ }^{*} \mathrm{P}<0.05$. Each independent experiment was repeated in triplicate.

siDOR-transfected group when compared with the control group and the group transfected with a negative control oligonucleotide $(\mathrm{p}<0.05)$ (Fig. 4A). The results indicate that DOR is capable of inhibiting breast cancer cell proliferation. To further clarify the mechanism used to affect the proliferation of human breast cancer cells, flow cytometry was performed to examine apoptosis and the cell cycle. The apoptotic rate was significantly increased in breast cancer cells after RNAi-mediated silencing of DOR when compared with the control group and the negative control oligonucleotide-transfected group $(\mathrm{p}<0.05)$. The expression levels of caspase-3, caspase- 9 and cytochrome $C$ protein were also elevated in breast cancer cells after DOR silencing when compared with the control group and the negative control oligonucleotide-transfected group. The expression levels of B-cell lymphoma 2 (Bcl-2) and B-cell lymphoma-extra large $(\mathrm{Bcl}-\mathrm{xL})$ were reduced in breast cancer cells after DOR silencing compared to those in the control group and the negative control oligonucleotide-transfected group. The majority of the tumour cells were arrested in the G1 phase after silencing of DOR $(\mathrm{p}<0.05)$. In addition, the levels of cyclin-dependent kinase 4 (CDK4) and cyclin D1 were decreased and the levels of p15 and p21 were increased in these cells (Fig. 4B-E). These results indicate that the inhibitory effect of DOR on breast 
A

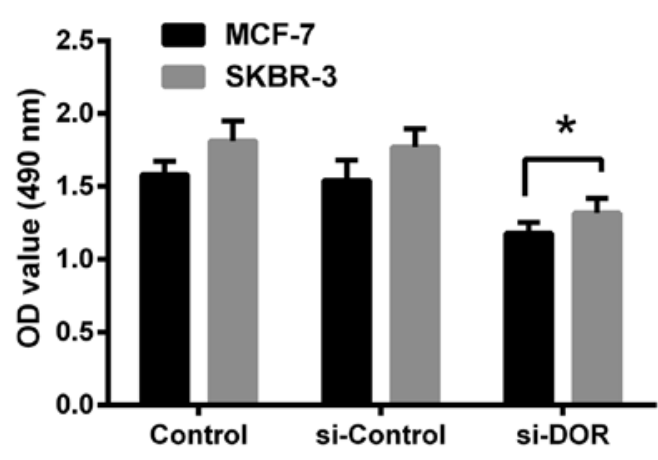

B
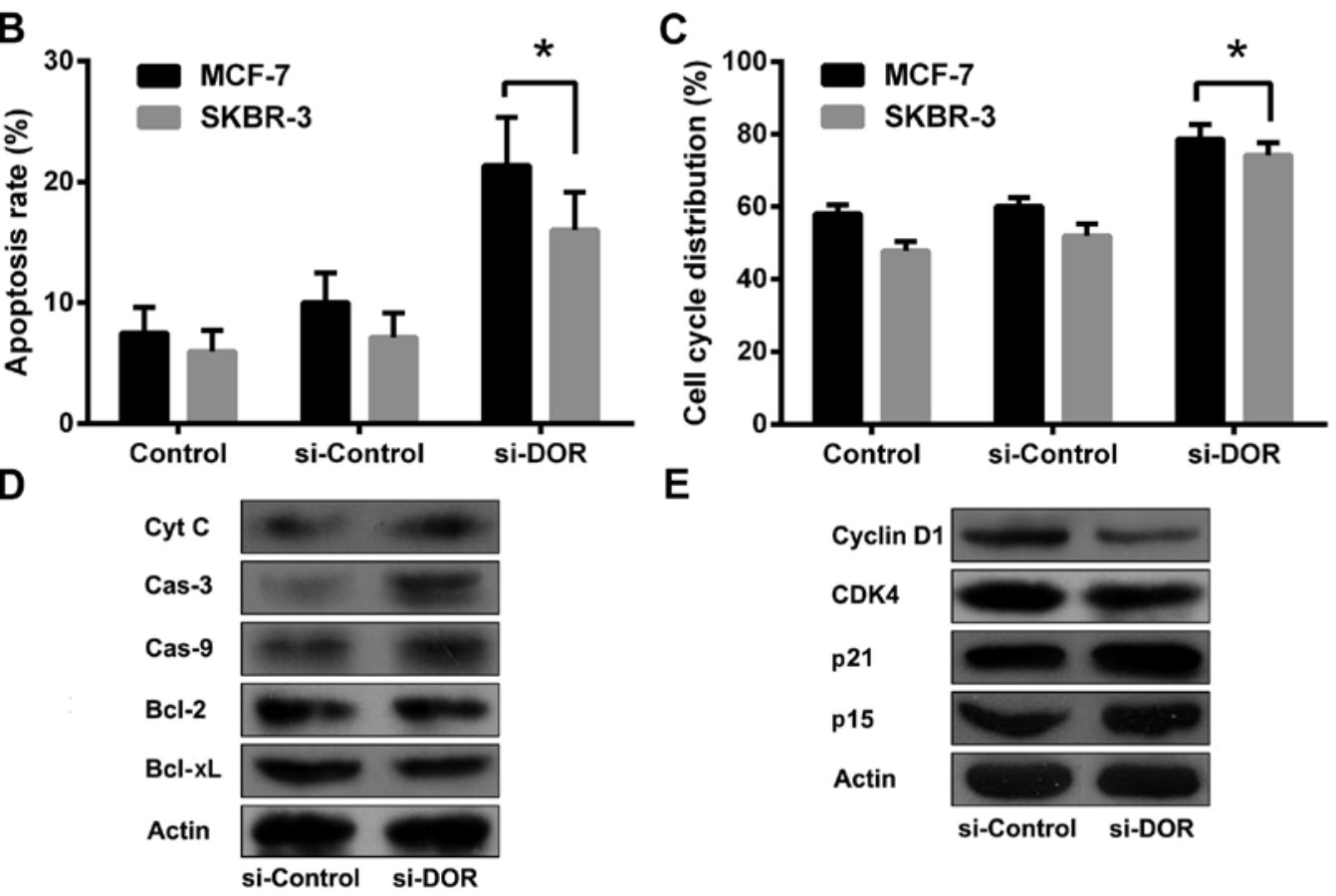

E

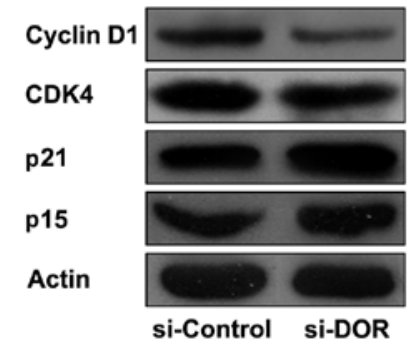

Figure 4. Downregulation of $\delta$-opioid receptor (DOR) inhibits the progression of breast cancer in vitro. MCF-7 and SKBR-3 cells were transfected for $48 \mathrm{~h}$. (A) The examination of cell viability using the MTT assay. (B) The analysis of apoptotic rate using flow cytometry. (C) The examination of the cell cycle by flow cytometry. (D) The examination of the changes in the expression of apoptosis-related proteins in MCF-7 cells using western blot analysis. (E) The examination of the changes in the expression of cell cycle-related proteins in MCF-7 cells by western blot analysis. Compared to the control group, ${ }^{*}$ p $<0.05$. Each independent experiment was repeated in triplicate.

cancer progression is closely related to the promotion of apoptosis and the blockage of cell cycle progression.

The effect of DOR on xenograft tumours in nude mice. Four weeks after the subcutaneous inoculation of tumour cells, the rate of tumour formation reached $100 \%$ in the si-Control group. The rate of tumour formation was $80 \%$ in the si-DOR group. The xenograft tumour grew more rapidly in the si-Control group than in the si-DOR group. In addition, the volume and weight of the xenograft tumours were significantly reduced in the si-DOR group compared to those in the si-Control group at all time points examined $(\mathrm{p}<0.05)$ (Fig. 5A-D). The results indicate that DOR inhibits tumourigenesis in nude mice.

Role of the PKC/ERK pathway in DOR-mediated effects on breast cancer progression. The phosphorylation levels of $\mathrm{PKC}$ and ERK proteins were examined to verify the specific role of the PKC/ERK signalling pathway in the DOR-mediated effects on human breast cancer progression. The results showed that activation of DOR led to significantly increased phosphorylation of the PKC protein in the cytoplasm $(\mathrm{p}<0.05)$. In addition, the intracellular phosphorylation level of the ERK proteins increased accordingly $(\mathrm{p}<0.05)$. The results demonstrate that DOR induced the phosphorylation of PKC and ERK proteins. However, treatment of the tumour cells with PKC-specific antagonist GF109203X (10 $\mu \mathrm{M})$ significantly inhibited the proliferation of tumour cells, regardless of DOR activation. Moreover, blocking the PKC pathway resulted in a decline in ERK phosphorylation levels (Fig. 6). The results demonstrate that the PKC pathway plays a critical role in the DOR-mediated effects on the progression of human breast cancer.

\section{Discussion}

Breast cancer is a common malignancy in women. Breast cancer originates in the breast ductal epithelium and mainly occurs in women between 40-60 years of age. Breast cancer ranks first among malignant tumours in women and is a major 
A

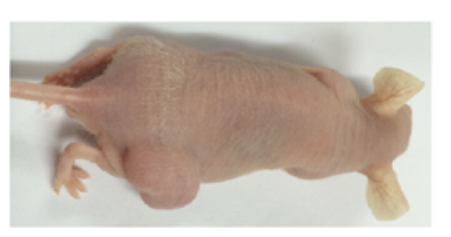

C

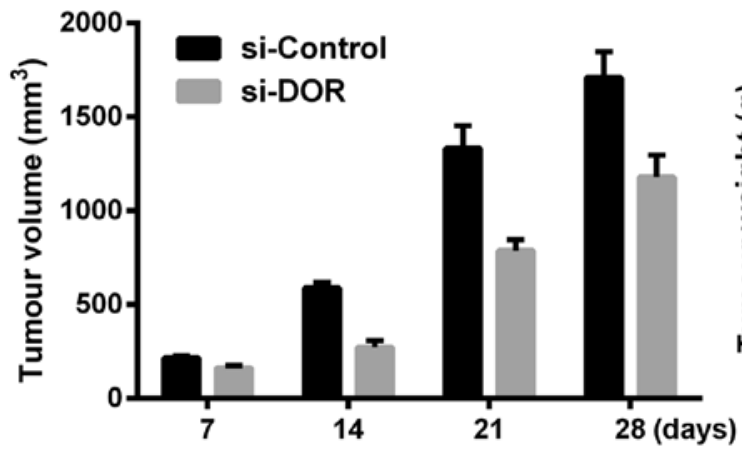

B

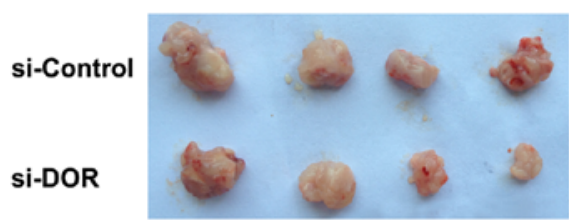

D

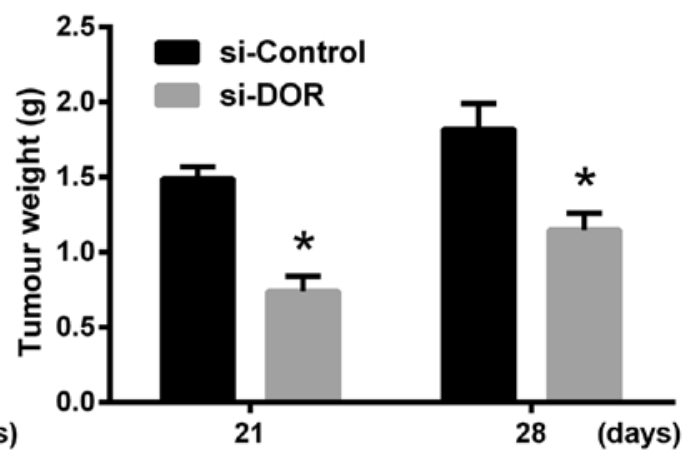

Figure 5. $\delta$-opioid receptor (DOR) inhibits tumour growth in nude mice. (A) Tumour-bearing nude mice. (B) The surgical resection of tumour tissues at 28 days after tumour cell inoculation. (C) The tumour volumes were measured at 7, 14, 21 and 28 days after inoculation with tumour cells. (D) The weights of the two tumour groups at 21 and 28 days after inoculation with tumour cells. Compared with the control group, ${ }^{*} \mathrm{p}<0.05$. Each independent experiment was repeated in triplicate.

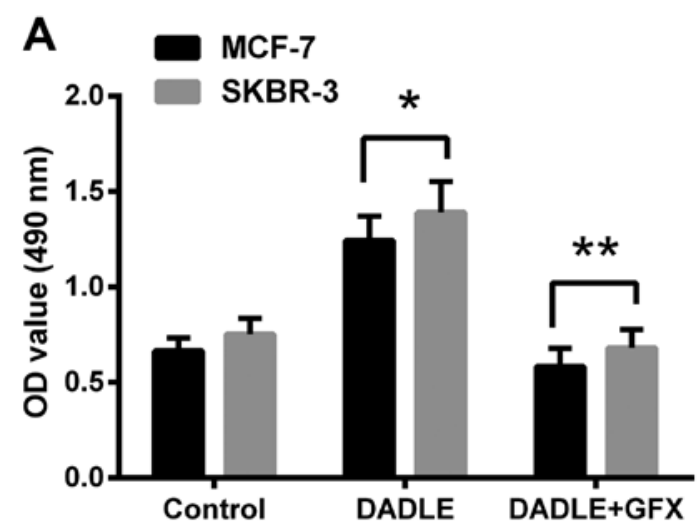

B

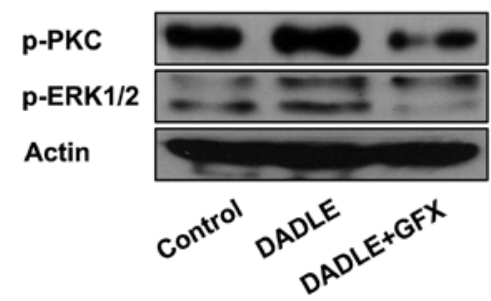

Figure 6. Role of the protein kinase C (PKC)/extracellular signal-regulated kinase (ERK) pathway in the $\delta$-opioid receptor (DOR)-mediated effects on breast cancer progression. MCF-7 and SKBR-3 cells were treated with $1.0 \mu \mathrm{M}$ of $\left[\mathrm{D}-\mathrm{Ala}^{2}, \mathrm{D}-\mathrm{Leu}^{5}\right]$ enkephalin (DADLE) or $10 \mu \mathrm{M}$ of GF109203X for $48 \mathrm{~h}$. (A) The examination of cell viability using the MTT assay. (B) The examination of PKC and ERK expression levels by western blot analysis Compared with the control group, ${ }^{*} \mathrm{p}<0.05$. Compared with the DADLE group, ${ }^{* *} \mathrm{p}<0.05$. Each independent experiment was repeated in triplicate.

disease that threatens women's health. The incidence of breast cancer continues to rise year after year $(31,32)$. An earlier detection of breast cancer correlates with an improved therapeutic efficacy. However, the pathogenesis of breast cancer is not entirely clear. Therefore, understanding the mechanisms underlying the development and progression of breast cancer is vital for breast cancer research and treatment.

Opioid receptors are the receptors for endogenous opioids and opioid analgesics (33). Opioid receptors belong to the superfamily of seven-transmembrane GPCRs, including $\mu, \kappa$ and $\delta$ receptors. The binding of opioid receptors to the natural ligands present in the organisms, such as endorphins, dynorphin, enkephalin and nociceptin, activates inhibitory $G$ proteins in the cytoplasmic face of the plasma membrane and triggers downstream molecular mechanisms through various signal transduction pathways (34). DOR is widely distributed in the heart (8), GI tract (9-11), immune system (12), reproductive system (13-15) and other tissues (35). Among all of the opioid receptor family members, DOR is believed to be the most closely related to cell survival and cell proliferation $(35,36)$ and is involved in the development and progression of certain malignant tumours. Studies that assessed the role of DOR in breast cancer are rare. In the present study, we found that DOR was highly expressed in human breast cancer tissues and cells. Subsequently, DOR expression was analysed in combination with the clinical pathological data of breast cancer patients. Positive DOR expression was closely related to lymph node metastasis, distant metastasis and the clinical stage of tumours. The results indicate that DOR is closely associated with the development, progression and clinical treatment of breast cancer.

Tumourigenesis is a multistep, prolonged interactive process that involves a variety of factors. Tumourigenesis is closely related to abnormal cell proliferation and apoptosis. A recent study showed that among the members of the opioid receptor superfamily, DOR is closely related to cell survival and proliferation (36). Zhao et al found that DOR activation promotes the proliferation of ventricular myocytes in neonatal rats (28). Avella et al found that endogenous opioid peptides 
promote liver cancer cell proliferation through DOR activation in the membrane of liver cells (37). The present study found that changes in DOR activity had a major impact on breast cancer cell proliferation and apoptosis. Activation of DOR promoted the proliferation of human breast cancer cells in vitro. The results of the present study are consistent with the aforementioned published research findings. However, a study conducted by Kuniyasu et al showed that methionine enkephalin inhibits the proliferation and invasion of colorectal cancer cells (17). This finding is contradictory to the results of the present study. The contradiction is likely due to the differences in tumour characteristics.

Delayed cell cycle progression is another important factor that affects the proliferation of tumour cells (38). The present study found that silencing DOR expression induced G1-phase arrest in breast cancer cells, thereby inhibiting tumour cell proliferation. Targeted silencing of DOR also induced apoptosis in breast cancer cells. In addition, the silencing of DOR expression effectively inhibited the progression of xenograft tumours in tumour-bearing nude mice. These results demonstrate that DOR is closely related to breast cancer progression.

It is well-known that PKC is widely distributed in living organisms. PKC regulates the proliferation and differentiation of various types of cells. Studies have shown that activated PKC inhibits apoptosis in various cell types (39-41). Oskoueian et al (24) and Li et al (25) found that PKC participates in breast cancer cell proliferation and differentiation. Recently, the consensus PKC phosphorylation sequence was discovered in DOR. The treatment of NG108-15 cells with DOR agonists activates $\mathrm{PKC}$ in a dose-dependent manner, whereas DOR-mediated PKC-activation is blocked by DOR antagonists (42). Therefore, DOR-mediated intracellular signalling pathways are closely related to the PKC pathway. The present study found that DOR activation in breast cancer cells led to the phosphorylation of the PKC protein. In addition, the phosphorylation level of ERK proteins was also increased. ERK belongs to the MAPK family and is related to cell proliferation, transformation and differentiation. The ERK pathway plays an important role in tumour development, progression and metastasis; thus, members of the pathway have become the molecular targets for novel cancer drug development (43). In recent years, studies have shown that DOR activation induces cell proliferation through the ERK signal transduction pathway (28-30). Zhu et al found that a DOR-specific agonist activated PKC and subsequently induced ERK activation (26). The results of the present study are consistent with the aforementioned previously reported results.

To prove that the PKC/ERK pathway is related to the effect of DOR on breast cancer progression, we artificially suppressed the PKC pathway. Inhibition of the PKC pathway resulted in the suppression of breast cancer cell proliferation, regardless of DOR activation. In addition, the phosphorylation level of ERK was decreased. These results indicate that the PKC and ERK pathways are involved in the apoptosis of MCF-7 cells induced by DOR downregulation; furthermore, DOR activation may promote the development and progression of breast cancer through the PKC/ERK pathway. A recent study found that DOR is related to tumour chemosensitivity (44). DOR is also involved in cell cycle progression. Further investigation is required to determine whether DOR affects chemotherapy resistance in breast cancer.

In summary, the present study demonstrated that DOR is highly expressed in breast cancer tissues and cells and is closely related to the progression of human breast cancer. Moreover, the present study suggests that the effects of DOR occur via the activation of the PKC/ERK signal transduction pathways. Future clarification of the mechanisms of DOR function is vital in order to understand the role of DOR in breast cancer progression and the development of treatment strategies focused on this potential therapeutic target.

\section{Acknowledgements}

This study was funded by the Health Department of the Guangxi Zhuang Autonomous Region (project no. Z2013488).

\section{References}

1. McPherson K, Steel CM and Dixon JM: ABC of breast diseases. Breast cancer-epidemiology, risk factors, and genetics. BMJ 321: 624-628, 2000

2. Benson JR and Jatoi I: The global breast cancer burden. Future Oncol 8: 697-702, 2012.

3. Anderson WF, Katki HA and Rosenberg PS: Incidence of breast cancer in the United States: Current and future trends. J Natl Cancer Inst 103: 1397-1402, 2011.

4. Kieffer BL, Befort K, Gaveriaux-Ruff C and Hirth CG: The delta-opioid receptor: Isolation of a cDNA by expression cloning and pharmacological characterization. Proc Natl Acad Sci USA 89: 12048-12052, 1992.

5. Evans CJ, Keith DE Jr, Morrison H, Magendzo K and Edwards RH: Cloning of a delta opioid receptor by functional expression. Science 258: 1952-1955, 1992.

6. Bzdega T, Chin H, Kim H, Jung HH, Kozak CA and Klee WA: Regional expression and chromosomal localization of the delta opiate receptor gene. Proc Natl Acad Sci USA 90: 9305-9309, 1993.

7. Simonin F, Befort K, Gavériaux-Ruff C, Matthes H, Nappey V, Lannes B, Micheletti G and Kieffer B: The human delta-opioid receptor: Genomic organization, cDNA cloning, functional expression, and distribution in human brain. Mol Pharmacol 46: 1015-1021, 1994.

8. Howells RD, Kilpatrick DL, Bailey LC, Noe M and Udenfriend S: Proenkephalin mRNA in rat heart. Proc Natl Acad Sci USA 83: 1960-1963, 1986

9. Fickel J, Bagnol D, Watson SJ and Akil H: Opioid receptor expression in the rat gastrointestinal tract: A quantitative study with comparison to the brain. Brain Res Mol Brain Res 46: 1-8, 1997.

10. Neidle A, Manigault I and Wajda IJ: Distribution of opiate-like substances in rat tissues. Neurochem Res 4: 399-410, 1979.

11. Wittert G, Hope P and Pyle D: Tissue distribution of opioid receptor gene expression in the rat. Biochem Biophys Res Commun 218: 877-881, 1996.

12. Radulović J and Janković BD: Opposing activities of brain opioid receptors in the regulation of humoral and cell-mediated immune responses in the rat. Brain Res 661: 189-195, 1994.

13. Kilpatrick DL, Howells RD, Noe M, Bailey LC and Udenfriend S: Expression of preproenkephalin-like mRNA and its peptide products in mammalian testis and ovary. Proc Natl Acad Sci USA 82: 7467-7469, 1985.

14. Chen CL, Chang CC, Krieger DT and Bardin CW: Expression and regulation of proopiomelanocortin-like gene in the ovary and placenta: Comparison with the testis. Endocrinology 118: 2382-2389, 1986.

15. Civelli O, Douglass J, Goldstein A and Herbert E: Sequence and expression of the rat prodynorphin gene. Proc Natl Acad Sci USA 82: 4291-4295, 1985.

16. Debruyne D, Leroy A, DE Wever O, Vakaet L, Mareel M and Bracke M: Direct effects of delta opioid receptor agonists on invasion-associated activities of HCT-8/E11 colon cancer cells. Anticancer Res 30: 9-17, 2010. 
17. Kuniyasu H, Luo Y, Fujii K, Sasahira T, Moriwaka Y, Tatsumoto N, Sasaki T, Yamashita Y and Ohmori H: CD10 enhances metastasis of colorectal cancer by abrogating the anti-tumoural effect of methionine-enkephalin in the liver Gut 59: 348-356, 2010.

18. Schreiber G, Campa MJ, Prabhakar S, O'Briant K, Bepler G and Patz EF Jr: Molecular characterization of the human delta opioid receptor in lung cancer. Anticancer Res 18: 1787-1792, 1998.

19. Cieślińska A, Sienkiewicz-Szłapka E, Kostyra E, Fiedorowicz E, Snarska J, Wroński K, Tenderenda M, Jarmołowska B and Matysiewicz M: $\mu$-Opioid receptor gene (OPRM1) polymorphism in patients with breast cancer. Tumour Biol 36: 4655-4660, 2015.

20. Molè D, Gentilin E, Gagliano T, Tagliati F, Bondanelli M, Pelizzo MR, Rossi M, Filieri C, Pansini G, degli Uberti EC, et al: Protein kinase C: A putative new target for the control of human medullary thyroid carcinoma cell proliferation in vitro. Endocrinology 153: 2088-2098, 2012.

21. Wickley PJ, Ding X, Murray PA and Damron DS: Propofolinduced activation of protein kinase $\mathrm{C}$ isoforms in adult rat ventricular myocytes. Anesthesiology 104: 970-977, 2006.

22. Saberi B, Shinohara M, Ybanez MD, Hanawa N, Gaarde WA Kaplowitz N and Han D: Regulation of $\mathrm{H}(2) \mathrm{O}(2)$-induced necrosis by $\mathrm{PKC}$ and AMP-activated kinase signaling in primary cultured hepatocytes. Am J Physiol Cell Physiol 295: C50-C63, 2008.

23. Ali AS, Ali S, El-Rayes BF, Philip PA and Sarkar FH: Exploitation of protein kinase $\mathrm{C}$ : A useful target for cancer therapy. Cancer Treat Rev 35: 1-8, 2009.

24. Oskoueian E, Abdullah N and Ahmad S: Phorbol esters from Jatropha meal triggered apoptosis, activated PKC- $\delta$, caspase- 3 proteins and down-regulated the proto-oncogenes in MCF-7 and HeLa cancer cell lines. Molecules 17: 10816-10830, 2012.

25. Li Z, Wang N, Fang J, Huang J, Tian F, Li C and Xie F: Role of PKC-ERK signaling in tamoxifen-induced apoptosis and tamoxifen resistance in human breast cancer cells. Oncol Rep 27: 1879-1886, 2012

26. Zhu M, Li M, Yang F, Ou X, Ren Q, Gao H, Zhu C and Guo J: Mitochondrial ERK plays a key role in $\delta$-opioid receptor neuroprotection against acute mitochondrial dysfunction. Neurochem Int 59: 739-748, 2011

27. Sancho $P$, Galeano E, Estañ MC, Gañán-Gómez I Boyano-Adánez MC and García-Pérez AI: Raf/MEK/ERK signaling inhibition enhances the ability of dequalinium to induce apoptosis in the human leukemic cell line K562. Exp Biol Med (Maywood) 237: 933-942, 2012.

28. Zhao M, Wang HX, Yang J, Su YH, Su RJ and Wong TM: delta-Opioid receptor stimulation enhances the growth of neonata rat ventricular myocytes via the extracellular signal-regulated kinase pathway. Clin Exp Pharmacol Physiol 35: 97-102, 2008.

29. Hayashi T, Tsao LI and Su TP: Antiapoptotic and cytotoxic properties of delta opioid peptide [D-Ala(2),D-Leu(5)] enkephalin in PC12 cells. Synapse 43: 86-94, 2002.

30. Bilecki W, Zapart G, Ligeza A, Wawrzczak-Bargiela A, Urbański MJ and Przewłocki R: Regulation of the extracellular signal-regulated kinases following acute and chronic opioid treatment. Cell Mol Life Sci 62: 2369-2375, 2005.
31. American Cancer Society: Cancer facts and figures 2006. http://www.cancer.org/downloads/STT/CAFF2006PWSecured. pdf. Accessed February 7, 2007.

32. Kuhl CK, Schrading S, Leutner CC, Morakkabati-Spitz N, Wardelmann E, Fimmers R, Kuhn W and Schild HH: Mammography, breast ultrasound, and magnetic resonance imaging for surveillance of women at high familial risk for breast cancer. J Clin Oncol 23: 8469-8476, 2005.

33. Brownstein MJ: A brief history of opiates, opioid peptides, and opioid receptors. Proc Natl Acad Sci USA 90: 5391-5393, 1993.

34. Al-Hasani R and Bruchas MR: Molecular mechanisms of opioid receptor-dependent signaling and behavior.Anesthesiology 115 1363-1381, 2011

35. Su TP: Delta opioid peptide[D- Ala(2),D-Leu(5)]enkephalin promotes cell survival. J Biomed Sci 7: 195-199, 2000.

36. Kim H, Lee SW, Park JS, Min JH and Kim HK: Genomic analysis of $\left[\mathrm{d}-\mathrm{Ala}^{2}, \mathrm{~d}-\mathrm{Leu}^{5}\right]$ enkephalin preconditioning in cortical neuron and glial cell injury after oxygen deprivation. Brain Res 1447: 91-105, 2012.

37. Avella DM, Kimchi ET, Donahue RN, Tagaram HR, McLaughlin PJ, Zagon IS and Staveley-O'Carroll KF: The opioid growth factor-opioid growth factor receptor axis regulates cell proliferation of human hepatocellular cancer. Am J Physiol Regul Integr Comp Physiol 298: R459-R466, 2010.

38. Stewart ZA, Westfall MD and Pietenpol JA: Cell-cycle dysregulation and anticancer therapy. Trends Pharmacol Sci 24: 139-145, 2003.

39. Allen TR, Krueger KD, Hunter WJ III and Agrawal DK: Evidence that insulin-like grow th factor-1 requires protein kinase C-epsilon, PI3-kinase and mitogen-activated protein kinase pathways to protect human vascular smooth muscle cells from apoptosis. Immunol Cell Biol 83: 651-667, 2005.

40. Agudo-López A, Miguel BG, Fernández I and Martínez AM: Role of protein kinase $\mathrm{C}$ and mitochondrial permeability transition pore in the neuroprotective effect of ceramide in ischemia-induced cell death. FEBS Lett 585: 99-103, 2011.

41. Peng Y,Hu Y,Feng N, Wang L and Wang X: L-3-n-butyl-phthalide alleviates hydrogen peroxide-induced apoptosis by PKC pathway in human neuroblastoma SK-N-SH cells. Naunyn Schmiedebergs Arch Pharmacol 383: 91-99, 2011.

42. Heiss A, Ammer H and Eisinger DA: delta-Opioid receptor-stimulated Akt signaling in neuroblastoma x glioma (NG108-15) hybrid cells involves receptor tyrosine kinase-mediated PI3K activation. Exp Cell Res 315: 2115-2125, 2009.

43. Huang D, Ding Y, Luo WM, Bender S, Qian CN, Kort E, Zhang ZF, VandenBeldt K, Duesbery NS, Resau JH, et al: Inhibition of MAPK kinase signaling pathways suppressed renal cell carcinoma growth and angiogenesis in vivo. Cancer Res 68: 81-88, 2008.

44. Tang B, Du J, Gao ZM, Liang R, Sun DG, Jin XL and Wang LM: DADLE suppresses the proliferation of human liver cancer HepG2 cells by activation of PKC pathway and elevates the sensitivity to cis-diammine dichloridoplatium. Zhonghua Zhong Liu Za Zhi 34: 425-429, 2012 (In Chinese). 